\title{
Influence of Interest in Appearance of Upper Eementary School Student on Makeup Behavior and Selfesteem
}

\author{
Jin-hee Ryu ${ }^{1}$, Young-Sam Kim ${ }^{2 *}$ \\ ${ }^{1}$ Department of Cosmetics Engineering, Konkuk University, Seoul, Korea \\ ${ }^{2}$ Department of Image Industry, Graduate School of Engineering, Konkuk University, Seoul, Korea
}

\author{
*Corresponding author: Young-Sam Kim, \\ Department of Image Industry, Graduate \\ School of Engineering, Konkuk University, \\ 120 Neungdong-ro, Gwangjin-gu, Seoul \\ 05029, Korea \\ Tel.: +82 24500463 \\ Email: gracehelen@konkuk.ac.kr
}

\section{Received October 31, 2019 \\ Revised March 05, 2020 \\ Accepted March 11, 2020}

Published March 30, 2020

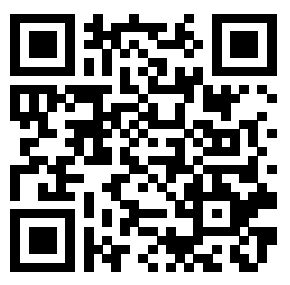

\begin{abstract}
Purpose: This study has further investigated the influence of their makeup behaviors on appearance satisfaction and self-esteem and aimed at investigating the influence of interest in appearance of the upper elementary school students on makeup behavior and self-esteem. Methods: A questionnaire survey was conducted for male and female upper elementary school students aged 11 to 12 years The collected data were analyzed using SPSS WIN 25.0 program, the frequency analysis, percentage, $t$-test, one-way ANOVA, $x^{2}$-test and regression were conducted, which derived the following results. Result: The results have suggested that the higher the interest in appearance by upper elementary school students, the higher is the appearance satisfaction. Furthermore, considering the perception on makeup in school, purchase subjects of cosmetics, purchase channels of cosmetics, reasons for makeup, and makeup skills among the actual use of cosmetics and makeup behaviors, students with a higher level of interest in appearance were determined as more independent and active in makeup than those in other groups, showing higher psychological expectation from makeup. Besides, the results suggest that the higher the psychological expectation, the higher are the appearance satisfaction and self-esteem. Conclusion: This study revealed that higher psychological expectation from makeup leads to higher self-esteem among upper elementary school students. The study results would contribute to forming good image, self-confidence, and sociability through appropriate use of cosmetics and good makeup culture by upper elementary school students rather than overcoming the negative perception on their own appearances.
\end{abstract}

Keywords: Elementary school student, Appearance interest, Makeup culture, Selfesteem, Makeup behavior

\section{Introduction}

과거에는 화장을 하는 여학생은 교칙 위반으로 처벌받았던 것과는 달리 이제는 초등학생들도 학부모에게 화장품 동의서를 받으면 학교 에서 화장에 대한 어떤 간섭도 받지 않는 사회적 현상과 식약처에서 는 어린이 화장품이 출시되면서 안정성 강화와 색조화장품 제품 관 심이 쏠리고 있으며, 초등학생의 외모 중시 열풍을 부추기거나 상술 이 더 심해지는 것이 아니냐는 우려가 커지고 어린이 화장품 관리 강 화로 지금은 어덜키즈(어덜트+키즈) 문화 확산으로 초등학생의 화장 에 대한 인식이 달라지고 있다.
아동들은 초등학교에 들어가면서 사회적 환경이 가정과 학교로 넓 혀짐에 따라 자신의 신체에 대한 관심이 높아져서 자신과 타인의 외 모를 비교하게 되면서 다른 사람에게 보이는 자신의 모습에 대해 관 심을 많이 가지게 된다(Park \& Kim, 2007). 이러한 관심은 실제로 초등학생들이 외모에 높은 관심을 보임과 동시에 외모로 깊은 고민 을 하는 것으로 나타났으며(Park, 2017), 특히 화장하는 이유가 자 신을 더 예쁘게 보이기 위함이라고 조사되기도 하였다(Park \& Kim, 2007).

이처럼 초등학생들 사이에서 화장을 한다는 것은 자신을 가꾸고 꾸미는 것에서 벗어나 또래 집단 사이에서 자신을 적극적으로 표현 
하고 드러내는 하나의 방법으로 자리 잡고 있다. 이렇게 외모에 대한 인식이 변함에 따라 초등학생의 올바른 자아상을 위해 많은 노력 또 한 필요로 하고 있다.

따라서 본 연구에서는 초등학교 고학년의 외모에 대한 관심이 급 격히 높아지는 시점에서 초등학교 고학년의 외모 관심 정도가 외모 만족도 및 화장품 사용행동에 어떤 영향을 미치는지 확인하고, 화장 행동이 외모만족도와 자아존중감에는 어떻게 영향을 미치는지를 알 아보고자 한다.

본 연구를 통해 초등학교 고학년의 화장품 사용실태와 화장행동을 파악함으로 초등학생들의 화장 문화가 교양 교육의 기초 자료로 활 용할 수 있을 것으로 기대한다. 또한, 화장행동이 외모만족도와 자아 존중감에는 미치는 영향을 살펴봄으로써, 성인기까지 영향을 미치는 초등학생의 화장 및 외모관리 행동에 대한 구체적인 자료를 제공할 수 있을 것이다.

\section{Methods}

\section{1. 연구참여자 및 기간}

본 연구는 초등학교 고학년의 외모관심도가 화장행동과 자아존 중감에 미치는 효과를 파악하고자 경기, 서울, 전주 등에 거주하는 11세-12세 남, 여 초등학생을 대상으로 설문조사를 실시하였으며, 2018년 11월 29일부터 12월 28일까지 4주 동안 설문조사 시 심층 면담을 병행하여 직접 설문지에 기입하는 방식으로 조사하였다.

설문지는 총 500 부를 배부하여 445 부가 회수되었으며, 그중 응답 이 정확하지 않은 23 부를 제외한 설문지 총 422 부를 최종 분석 자료 로 활용하였다.

\section{2. 측정 도구}

1) 설문지 구성

본 연구에서 초등학교 고학년의 외모관심도가 화장행동과 자아 존중감에 미치는 영향 연구를 위해 사용된 설문지는 Jung (2013), Park (2017), Park \& Kim (2007)의 선행연구에서 실시된 측정항목 을 토대로 본 연구의 목적에 맞게 문항을 수정, 보완하여 재구성하여 제작한 설문지를 사용하였다.

\section{2) 자료 분석}

본 연구의 위한 자료는 Statistical Package for the Social Science (SPSS) WIN 25.0 프로그램을 이용하여 분석하였으며, 분 석 기법은 연구참여자의 일반적 특성을 알아보기 위해 빈도와 백분 율을 구하였다. 또한, 초등학교 고학년의 외모관심도와 외모만족도, 화장품 사용실태 및 화장행동, 화장에 대한 심리적 기대감, 그리고 자아존중감을 살펴보기 위하여 일원 변량분석(one-way ANOVA)와 $t$-test, 그리고 Chi-square $\left(\chi^{2}\right)$-test를 실시하였다. 초등학교 고학 년의 외모관심도 수준에 따라 화장품 사용실태 및 화장행동을 살펴 보기 위해 $\chi^{2}$-test를, 외모관심도와 외모만족도 및 화장에 대한 심리 적 기대감과의 관계, 화장에 대한 심리적 기대감과 외모만족도 및 자 아존중감과의 관계를 해석하기 위해 correlation (상관관계분석)을, 외모관심도가 외모만족도와 화장에 대한 심리적 기대감에 미치는 영 향과 화장에 대한 심리적 기대감이 외모만족도 및 자아존중감에 미 치는 영향을 알아보기 위해 regression (회귀분석)을 실시하였다.

\section{Results and Discussion}

\section{1. 연구참여자의 일반적 특성}

Table 1. General characteristics of participants

\begin{tabular}{llcc}
\hline Classification & & Frequency & Percentage (\%) \\
Grade & th & 168 & 39.8 \\
& 6 th & 254 & 60.2 \\
Gender & Male & 212 & 50.2 \\
& Female & 210 & 49.8 \\
Sibling number & 1 & 45 & 10.7 \\
& 2 & 271 & 64.2 \\
& More than 3 & 106 & 25.1 \\
Average monthly allowance & Less than 30,000 & 339 & 80.3 \\
(unit: won) & Less than 30,000-50,000 & 61 & 14.5 \\
& Less than 50,000-70,000 & 11 & 2.6 \\
Total & Less than 70,000-100,000 & 6 & 1.4 \\
\hline
\end{tabular}


본 연구의 연구참여자의 일반적 특성은 Table 1 과 같다.

총 422 명 중 학년별로는 6학년이 $60.2 \%$ 로 5 학년 $39.8 \%$ 보다 많 았다. 성별로는 남학생이 $50.2 \%$, 여학생은 $49.8 \%$ 로 유사한 분포를 보였다. 형제 수별로는 2 명이 $64.2 \%$ 로 절반 이상을 차지하였으며, 다음으로 3 명 이상 $25.1 \%, 1$ 명 $10.7 \%$ 순이었다. 월평균 용돈별로 는 3만원 미만이 $80.3 \%$ 로 대부분이었으며, 다음으로 3-5만원 미 만 $14.5 \%, 5-7$ 만원 미만 $2.6 \%, 7-10$ 만원 미만 $1.4 \%, 10$ 만원 이 상 $1.2 \%$ 순으로 나타났다. 이는 학년은 6 학년이 조금 더 많았으며, 성별은 비슷하였고, 형제 수는 2 명 이상이 많았으며 월평균 용돈은 3 만원 미만이 가장 많았다.

\section{2. 측정 도구의 신뢰도 검증}

본 연구의 측정도구의 신뢰도를 검증된 Table 2 와 같이 Cronbach $\alpha$ 가 외모관심도 0.89 , 화장에 대한 심리적 기대감 0.96 ,
자아존중감 0.90 , 외모만족도 0.83 으로, 모두 0.60 이상으로 나왔 으며, 이에 본 연구의 측정도구는 신뢰할 수 있는 수준임을 볼 수 있다.

\section{3. 화장행동}

초등학교 고학년이 화장을 하는 이유에 대해 살펴본 결과는 Table 3 와 같이 화장은 피부보호를 위해서 하는 학생이 $31.2 \%$ 로 가장 많았으며, 다음으로 기타 $25.9 \%$, 예뼈 보이기 위해서 $20.6 \%$, 부모님의 권유 $10.6 \%$, '친구들이 하기 때문에'와 나의 개성을 강조 하기 위해서 $4.1 \%$ 순으로 나타났다.

학년별로는 5 학년 학생이 6 학년 학생보다 화장을 부모님의 권유 에 의해 많이 하였고, 6 학년 학생은 5 학년 학생보다 피부보호를 위 해서 많이 하였으나 유의미한 차이는 아니었다. 성별로는 남학생이 여학생보다 화장을 피부보호를 위해서 많이 하였고, 여학생은 남학

Table 2. Measurement tool reliability

\begin{tabular}{lccc}
\hline Classification & & Number of questions & Cronbach's $\alpha$ \\
Interest in appearance & & 10 & 0.89 \\
\multicolumn{2}{l}{$\begin{array}{l}\text { Psychological expectations from makeup } \\
\text { General self }\end{array}$} & 16 & 0.96 \\
& Societal self & 9 & 0.81 \\
Self-esteem & Home self & 7 & 0.83 \\
& School self & 10 & 0.82 \\
Appearance satisfaction & Total self-esteem & 8 & 0.62 \\
\hline
\end{tabular}

Table 3. Reason for wearing makeup

\begin{tabular}{|c|c|c|c|c|c|c|c|c|c|c|c|}
\hline \multicolumn{2}{|l|}{ Classification } & $\begin{array}{l}\text { To look } \\
\text { pretty }\end{array}$ & $\begin{array}{c}\text { Peer } \\
\text { pressure }\end{array}$ & $\begin{array}{l}\text { Individuality } \\
\text { emphasis }\end{array}$ & Curiosity & $\begin{array}{l}\text { Parental } \\
\text { persuasion }\end{array}$ & $\begin{array}{c}\text { Skin } \\
\text { protection }\end{array}$ & Others & Total & $x^{2}(d f)$ & $p$ \\
\hline \multirow{2}{*}{ Grade } & 5 th & $\begin{array}{c}12 \\
(20.7)\end{array}$ & $\begin{array}{c}4 \\
(6.9)\end{array}$ & $\begin{array}{c}0 \\
(0.0)\end{array}$ & $\begin{array}{c}2 \\
(3.4)\end{array}$ & $\begin{array}{c}8 \\
(13.8)\end{array}$ & $\begin{array}{c}13 \\
(22.4)\end{array}$ & $\begin{array}{c}19 \\
(32.8)\end{array}$ & $\begin{array}{c}58 \\
(34.1)\end{array}$ & \multirow{2}{*}{$\begin{array}{l}9.91 \\
(6)\end{array}$} & \multirow{2}{*}{0.129} \\
\hline & 6 th & $\begin{array}{c}23 \\
(20.5)\end{array}$ & $\begin{array}{c}3 \\
(2.7)\end{array}$ & $\begin{array}{c}7 \\
(6.3)\end{array}$ & $\begin{array}{c}4 \\
(3.6)\end{array}$ & $\begin{array}{l}10 \\
(8.9)\end{array}$ & $\begin{array}{c}40 \\
(35.7)\end{array}$ & $\begin{array}{c}25 \\
(22.3)\end{array}$ & $\begin{array}{l}112 \\
(65.9)\end{array}$ & & \\
\hline \multirow{2}{*}{ Gender } & Male & $\begin{array}{c}0 \\
(0.0)\end{array}$ & $\begin{array}{c}0 \\
(0.0)\end{array}$ & $\begin{array}{c}1 \\
(1.9)\end{array}$ & $\begin{array}{c}0 \\
(0.0)\end{array}$ & $\begin{array}{c}12 \\
(22.6)\end{array}$ & $\begin{array}{c}23 \\
(43.4)\end{array}$ & $\begin{array}{c}17 \\
(32.1)\end{array}$ & $\begin{array}{c}53 \\
(31.2)\end{array}$ & \multirow{2}{*}{$\begin{array}{c}30.07^{* * *} \\
(6)\end{array}$} & \multirow{2}{*}{0.000} \\
\hline & Female & $\begin{array}{c}35 \\
(29.9)\end{array}$ & $\begin{array}{c}7 \\
(6.0)\end{array}$ & $\begin{array}{c}6 \\
(5.1)\end{array}$ & $\begin{array}{c}6 \\
(5.1)\end{array}$ & $\begin{array}{c}6 \\
(5.1)\end{array}$ & $\begin{array}{c}30 \\
(25.6)\end{array}$ & $\begin{array}{c}27 \\
(23.1)\end{array}$ & $\begin{array}{l}117 \\
(68.8)\end{array}$ & & \\
\hline \multirow{3}{*}{ Sibling number } & 1 & $\begin{array}{c}5 \\
(25.0)\end{array}$ & $\begin{array}{c}2 \\
(10.0)\end{array}$ & $\begin{array}{c}0 \\
(0.0)\end{array}$ & $\begin{array}{c}1 \\
(5.0)\end{array}$ & $\begin{array}{c}1 \\
(5.0)\end{array}$ & $\begin{array}{c}5 \\
(25.0)\end{array}$ & $\begin{array}{c}6 \\
(30.0)\end{array}$ & $\begin{array}{c}20 \\
(11.8)\end{array}$ & \multirow{3}{*}{$\begin{array}{c}15.03 \\
(12)\end{array}$} & \multirow{3}{*}{0.240} \\
\hline & 2 & $\begin{array}{c}18 \\
(17.1)\end{array}$ & $\begin{array}{c}5 \\
(4.8)\end{array}$ & $\begin{array}{c}4 \\
(3.8)\end{array}$ & $\begin{array}{c}4 \\
(3.8)\end{array}$ & $\begin{array}{c}12 \\
(11.4)\end{array}$ & $\begin{array}{c}40 \\
(38.1)\end{array}$ & $\begin{array}{c}22 \\
(21.0)\end{array}$ & $\begin{array}{l}105 \\
(61.8)\end{array}$ & & \\
\hline & More than 3 & $\begin{array}{c}12 \\
(26.7)\end{array}$ & $\begin{array}{c}0 \\
(0.0)\end{array}$ & $\begin{array}{c}3 \\
(6.7)\end{array}$ & $\begin{array}{c}1 \\
(2.2)\end{array}$ & $\begin{array}{c}5 \\
(11.1)\end{array}$ & $\begin{array}{c}8 \\
(17.8)\end{array}$ & $\begin{array}{c}16 \\
(35.6)\end{array}$ & $\begin{array}{c}45 \\
(26.5)\end{array}$ & & \\
\hline \multirow{2}{*}{$\begin{array}{l}\text { Average monthly } \\
\text { allowance } \\
\text { (unit: won) }\end{array}$} & Less than 30,000 & $\begin{array}{c}22 \\
(16.9)\end{array}$ & $\begin{array}{c}4 \\
(3.1)\end{array}$ & $\begin{array}{c}5 \\
(3.8)\end{array}$ & $\begin{array}{c}6 \\
(4.6)\end{array}$ & $\begin{array}{c}13 \\
(10.0)\end{array}$ & $\begin{array}{c}44 \\
(33.8)\end{array}$ & $\begin{array}{c}36 \\
(27.7)\end{array}$ & $\begin{array}{c}130 \\
(76.5)\end{array}$ & \multirow{2}{*}{$\begin{array}{l}9.15 \\
(6)\end{array}$} & \multirow{2}{*}{0.166} \\
\hline & More than 30,000 & $\begin{array}{c}13 \\
(32.5)\end{array}$ & $\begin{array}{c}3 \\
(7.5)\end{array}$ & $\begin{array}{c}2 \\
(5.0)\end{array}$ & $\begin{array}{c}0 \\
(0.0)\end{array}$ & $\begin{array}{c}5 \\
(12.5)\end{array}$ & $\begin{array}{c}9 \\
(22.5)\end{array}$ & $\begin{array}{c}8 \\
(20.0)\end{array}$ & $\begin{array}{c}40 \\
(23.5)\end{array}$ & & \\
\hline \multicolumn{2}{|c|}{ Total } & $\begin{array}{c}35 \\
(20.6)\end{array}$ & $\begin{array}{c}7 \\
(4.1)\end{array}$ & $\begin{array}{c}7 \\
(4.1)\end{array}$ & $\begin{array}{c}6 \\
(3.5)\end{array}$ & $\begin{array}{c}18 \\
(10.6)\end{array}$ & $\begin{array}{c}53 \\
(31.2)\end{array}$ & $\begin{array}{c}44 \\
(25.9)\end{array}$ & $\begin{array}{c}170 \\
(100.0)\end{array}$ & & \\
\hline
\end{tabular}

${ }^{* * *} p<0.001$. 
생보다 예쁘게 보이기 위해서 많이 하였으며, 성별로 유의미한 차 이가 나타났다 $(p<0.001)$. 이는 Park \& $\operatorname{Kim}$ (2007)의 화장품을 왜 사용하는지 조사한 결과 남학생은 피부보호를 위해서가 높았으며, 여학생의 경우 예쁘게 보이기 위해서가 높게 나왔다는 연구결과와 유사하였다.

형제 수별로는 형제가 2 명인 학생이 다른 학생보다 화장을 피부 보호를 위해서 많이 하였고, 3 명 이상인 학생은 다른 학생보다 예 쁘게 보이기 위해서 많았으나, 형제 수 별로 유의미한 차이를 보이 지 않았다. 월평균 용돈별로는 3 만원 미만인 학생이 3 만원 이상인 학생보다 화장을 피부보호를 위해서 많이 하였고, 3 만원 이상의 학 생은 3 만원 미만에 학생보다 예쁘게 보이기 위해서 많이 하였으나 통계적으로는 유의미한 차이를 보이지 않았다.

이상과 같이 초등학교 고학년은 화장을 피부보호를 위해서 가장 많았으며, 남학생이 여학생보다 화장을 피부보호를 위해서 많이 하 였다.

화장행동 분석 결과 Park (2017)과 다른 연구결과를 도출하였 다. 이는 초등학교 고학년이 예뻐지기 위해서 화장행동을 보이는
예전의 시각에서 TV나 인터넷, 대중매체를 통해 화장법도 배우고 화장한 모습을 동영상이나 사진으로 찍어 친구들과 공유함으로써, 외모에 대해 관심 받고 인정받는 것을 즐긴다(Oh et al., 2012). 이 러한 초등학생의 사회적인 현상으로 요즘 화장의 트렌드에 맞춰 '한 듯 안 한 듯한 투명화장을 선호하는 영향력으로 화장은 색조에 관 심 있을 거라는 관점에서 피부에 관심이 있다는 결론은 어떤 면에 서 의미 있는 영향을 미쳤다고 판단된다.

\section{4. 화장에 대한 심리적 기대감}

초등학교 고학년의 화장에 대한 심리적 기대감에 관해 알아본 결 과는 Table 4 와 같이 5 점 만점 중 전체 평균이 1.88 로, 초등학교 고 학년은 화장에 대한 심리적 기대감이 낮은 것으로 나타났다.

학년별로는 6 학년 학생이 5 학년 학생보다 화장에 대한 심리적 기대감이 높았으며, 학년별로 유의미한 차이가 나타났다 $(p<0.05)$. 성별로는 여학생이 남학생보다 화장에 대한 심리적 기대감이 높았 으며, 성별로 유의미한 차이가 나타났다 $(p<0.001)$. 이는 초등학생 의 화장할 때 심리적 기대요인에 대한 연구결과 초등학교 고학년의

Table 4. Psychological expectations from makeup

\begin{tabular}{|c|c|c|c|c|c|c|}
\hline \multicolumn{2}{|l|}{ Classification } & $\mathrm{N}$ & Mean & SD & $t$ or $F$ & $p$ \\
\hline \multirow{2}{*}{ Grade } & 5 th & 168 & 1.77 & 0.89 & \multirow{2}{*}{$-1.98^{*}$} & \multirow{2}{*}{0.048} \\
\hline & 6 th & 254 & 1.95 & 0.93 & & \\
\hline \multirow{2}{*}{ Gender } & Male & 212 & 1.46 & 0.57 & \multirow{2}{*}{$-10.60^{* * *}$} & \multirow{2}{*}{0.000} \\
\hline & Female & 210 & 2.31 & 1.01 & & \\
\hline \multirow{3}{*}{ Sibling (s) (number) } & 1 & 45 & 1.88 & 0.99 & \multirow{3}{*}{0.11} & \multirow{3}{*}{0.900} \\
\hline & 2 & 271 & 1.87 & 0.90 & & \\
\hline & More than 3 & 106 & 1.92 & 0.94 & & \\
\hline \multirow{2}{*}{ Average monthly allowance } & Less than 30,000 won & 339 & 1.83 & 0.89 & \multirow{2}{*}{$-2.29^{*}$} & \multirow{2}{*}{0.022} \\
\hline & More than 30,000 won & 83 & 2.09 & 1.03 & & \\
\hline \multicolumn{2}{|c|}{ Total } & 422 & 1.88 & 0.92 & & \\
\hline
\end{tabular}

${ }^{*} p<0.05 ;{ }^{* * *} p<0.001$; SD, standard deviation.

\section{Table 5. Self-esteem}

\begin{tabular}{|c|c|c|c|c|c|c|}
\hline \multicolumn{2}{|l|}{ Classification } & $N$ & Mean & SD & $t$ or $F$ & $p$ \\
\hline \multirow{2}{*}{ Grade } & 5 th & 168 & 3.57 & 0.52 & \multirow{2}{*}{$-2.07^{*}$} & \multirow{2}{*}{0.040} \\
\hline & 6th & 254 & 3.67 & 0.45 & & \\
\hline \multirow{2}{*}{ Gender } & Male & 212 & 3.54 & 0.46 & \multirow{2}{*}{$-3.95^{* * *}$} & \multirow{2}{*}{0.000} \\
\hline & Female & 210 & 3.72 & 0.49 & & \\
\hline \multirow{3}{*}{ Sibling (s) (number) } & 1 & 45 & 3.65 & 0.59 & \multirow{3}{*}{0.10} & \multirow{3}{*}{0.901} \\
\hline & 2 & 271 & 3.63 & 0.48 & & \\
\hline & More than 3 & 106 & 3.62 & 0.44 & & \\
\hline \multirow{2}{*}{ Average monthly allowance } & Less than 30,000 won & 339 & 3.60 & 0.46 & \multirow{2}{*}{$-2.14^{*}$} & \multirow{2}{*}{0.034} \\
\hline & More than 30,000 won & 83 & 3.74 & 0.53 & & \\
\hline \multicolumn{2}{|c|}{ Total } & 422 & 3.63 & 0.48 & & \\
\hline
\end{tabular}

${ }^{*} p<0.05 ;{ }^{* * *} p<0.001 ; \mathrm{SD}$, standard deviation. 
화장에 관한 관심도와 인지도가 성별에 따라 큰 차이를 보이므로 Park \& Kim (2007) 연구결과와 화장에 관한 관심도가와 인지도가 성별에 따라 큰 차이를 보이는 것은 유사하였지만 반면에 초등학교 고학년 남녀 모두 심리적 기대감은 낮은 것으로 나타났다. 이는 초 등학교 부모와 어른들의 일방적인 질책, 제한에서 오는 화장이 무 조건 나쁘다는 부정적인 시각으로 비롯된 결과라 생각된다.

형제 수별로는 형제가 3 명 이상인 학생이 화장에 대한 심리적 기 대감이 가장 높았고, 2 명인 학생은 다른 학생보다 화장에 대한 심 리적 기대감이 낮았으나 유의미한 차이는 아니었다. 월평균 용돈별 로는 3 만원 이상의 학생이 3 만원 미만에 학생보다 화장에 대한 심 리적 기대감이 높았으며, 월평균 용돈별로 유의미한 차이가 나타났 다( $p<0.05)$.

이상과 같이 초등학교 고학년은 화장에 대한 심리적 기대감이 낮 았으며, 6 학년 학생과 여학생, 그리고 월평균 용돈이 3 만원 이상인 학생이 다른 학생보다 화장에 대한 심리적 기대감이 높았다.

\section{5. 자아존중감}

초등학교 고학년의 자아존중감에 관해 알아본 결과는 Table 5 와 같이 5 점 만점 중에서 전체 평균이 3.63 으로, 초등학교 고학년은 자아존중감이 높은 것으로 나타났다.

학년별로는 6 학년 학생이 5 학년 학생보다 자아존중감이 더 높았 으며, 학년별로 유의미한 차이가 나타났다 $(p<0.05)$. 성별로는 여학 생이 남학생보다 자아존중감이 더 높았으며, 성별로 유의미한 차이 가 나타났다 $(p<0.001)$.

형제 수별로는 형제가 적은 학생일수록 자아존중감이 더 높게 보 였으며, 통계적으로는 유의미한 차이가 나타나지 않았다. 월평균 용돈에 따라 3 만원 이상의 학생이 3 만원 미만에 학생보다 자아존 중감이 더 높았으며, 월평균 용돈별로 유의미한 차이가 나타났다 $(p<0.05)$.

이상과 같이 초등학교 고학년은 자아존중감이 높았으며, 6 학년 학생과 여학생, 그리고 월평균 용돈이 3 만원 이상인 학생이 다른
학생보다 자아존중감이 더 높았다.

\section{6. 외모관심도가 외모만족도에 미치는 영향}

초등학교 고학년의 외모관심도와 외모만족도와의 관계에 관해 알아본 결과는 Table 6 와 같다. 외모관심도는 외모만족도와 통계적 으로 유의미한 정적 상관관계가 보였다 $(p<0.001)$. 따라서 초등학교 고학년은 외모관심도가 높을수록 외모만족도가 높음을 알 수 있다.

본 연구 결과와 유사하게 사회생활에 영향을 미치며 관심도가 높 은 사람이 외모만족도 또한 높게 나타났다(Kwon \& Heo, 2019). 이는 성인 여성의 전유물이었던 화장문화의 세대가 급격히 낮아지 면서 여자 어린이도 $43.6 \%$ 가 화장을 한다고 할 만큼 화장문화의 세대가 낮아지고 있다(Kim \& Kim, 2014). 초등학교 고학년은 외 모관심도가 높아지면서 올바른 화장품 사용과 건전한 화장문화로 타인에게 자신을 자신이 원하는 모습으로 보이도록 하기 위해 노력 해야 한다. 이러한 것을 통해 자신감과 사회성 등이 증가함에 따라 외모만족도도 높아진다고 생각 되어진다.

\section{7. 외모관심도 수준에 따른 화장품 사용실태와 화장행동}

초등학교 고학년의 외모관심도 수준에 따라 사용하고 있는 화장 품에 관해 알아본 결과는 Table 7 과 같다.

외모관심도 수준이 낮은 학생일수록 화장품을 전혀 사용하지 않 았고, 외모관심도 수준이 높은 학생일수록 기초화장품과 색조화장 품 모두 많이 사용하였으며, 외모관심도 수준별로 유의미한 차이를 보였다 $(p<0.001)$. 따라 외모관심도 수준이 높은 학생일수록 기초화 장품과 색조화장품 모두 많이 사용하고 있음을 알 수 있다.

이런 화장품 사용실태는 화장행동으로 이어지는데. Kang (2014)의 자신이 처신하는 방법에 관한 행동적 역량 측정에서는 자 신의 행동방식에 만족하지 못할수록, 학생들이 외모관리를 열심히 하며, 전반적으로 자아가치감이 낮은 여자 청소년들이 화장행동을 적극적으로 하는 것으로 나타났다는 다른 연구결과는 관심도와 만 족도가 미치는 영향이 각각 다름을 나타내고 있다.

Table 6. Relation between appearance interest and appearance satisfaction

\begin{tabular}{lc}
\hline Classification & Appearance satisfaction \\
Appearance interest & $0.457^{* * *}(0.000)$ \\
\hline${ }^{* * *} p<0.001$. &
\end{tabular}

Table 7. Cosmetics used according to level of interest in appearance

\begin{tabular}{llcccccc}
\hline Division & & $\begin{array}{c}\text { Never use } \\
\text { makeup }\end{array}$ & $\begin{array}{c}\text { Only } \\
\text { foundation }\end{array}$ & $\begin{array}{c}\text { Only color } \\
\text { makeup }\end{array}$ & $\begin{array}{c}\text { Both foundation } \\
\text { and color makeup }\end{array}$ & $x^{2}$ (df) & $p$ \\
Level of interest & High & $35(32.7)$ & $38(35.5)$ & $10(9.3)$ & $24(22.4)$ & $107(25.4)$ & \\
in appearance & Moderate & $95(58.3)$ & $62(38.0)$ & $2(1.2)$ & $4(2.5)$ & $163(38.6)$ & $107.22^{* * *}(6) 0.000$ \\
& Low & $122(80.3)$ & $29(19.1)$ & $1(0.7)$ & $0(0.0)$ & $152(36.0)$ & \\
\multicolumn{1}{c}{ Total } & & $252(59.7)$ & $129(30.6)$ & $13(3.1)$ & $28(6.6)$ & $422(100.0)$ \\
\hline
\end{tabular}

${ }^{* * *} p<0.001$. 


\section{Conclusion}

본 연구는 초등학교 고학년의 외모관심도가 화장행동과 자아존 중감에 미치는 영향을 파악하고자 경기, 서울, 전주 등에 거주하는 11 세 -12 세 남, 여 초등학교 고학년을 대상으로 일반적 특성인 학 년, 성별, 1달 평균 용돈, 형제, 자매, 남매 관계, 따른 초등학교 고 학년의 외모에 대한 관심과 화장행동, 화장실태를 알아본 후, 초등 학교 고학년의 외모만족도와 자아존중감과 화장의 기대요인에 대 해 파악하고 외모 관심 정도는 외모만족도와 화장품 사용행동 및 화장할 때의 심리적 기대감에 어떤 영향을 미치는지와 화장할 때의 심리적 기대감은 외모만족도와 자아존중감에 어떤 영향을 미치는 지를 분석하였다.

2018년 11월 29일부터 12월 28일까지 4주 동안 설문조사를 실 시하였고, 연령대에 따른 여러 제약으로 직접 설문지에 기입하였 고, 지역적으로 면담을 병행할 수 없었던 분들은 우편 발송된 설문 지를 직접 기입해서 우편으로 참여하는 방식으로 설문지 총 422 부를 최종 분석 자료로 활용하였으며, 연구를 위한 자료는 SPSS WIN 25.0 프로그램을 이용하여 분석하였으며, 연구참여자의 일반 적 특성을 알아보기 위해 빈도와 백분율을, 초등학교 고학년의 외 모관심도와 외모만족도, 화장품 사용실태 및 화장행동, 화장에 대 한 심리적 기대감, 그리고 자아존중감을 알아보기 위해 one-way ANOVA와 $t$-test, 그리고 $\chi^{2}$-test를 또한 초등학교 고학년의 외 모관심도 수준에 따라 화장품 사용실태 및 화장행동을 살펴보기 위 해 $\chi^{2}$-test를, 외모관심도와 외모만족도 및 화장에 대한 심리적 기 대감과의 관계, 화장에 대한 심리적 기대감과 외모만족도 및 자아 존중감과의 관계를 파악하기 위해 외모관심도가 외모만족도와 화 장에 대한 심리적 기대감에 미치는 영향과 화장에 대한 심리적 기 대감이 외모만족도 및 자아존중감에 미치는 영향을 살펴보기 위해 Regression을 실시하여, 다음과 같은 결과를 얻을 수 있었다.

초등학교 고학년의 외모관심도가 화장행동과 자아존중감에 미치 는 영향을 검증한 결과를 토대로 다음과 같은 제언을 한다.

첫째, 초등학교 고학년의 일반적 특성에 따라 화장품 사용행동과 화장행동, 화장할 때의 심리적 기대감에 영향을 미친다.

조사 결과 초등학교 고학년은 화장에 대한 심리적 기대감이 미비 했으며, 그 중 6 학년 학생과 여학생, 그리고 월평균 용돈이 3 만원 이상인 학생이 다른 학생보다 화장에 대한 심리적 기대감이 높으므 로 나타났다. Park \& Kim (2007)의 초등학생 남녀 모두 심리적 기 대감은 낮은 것으로 규정한 연구와 유사한 결과이다. 이는 초등학 생 부모와 어른들의 일방적인 질책, 제한부터 오는 화장이 무조건 적으로 나쁘다는 부정적인 시각으로 비롯되어 절반 이상의 초등학 교 고학년이 학교 내 화장에 대해 기초화장품 외 화장을 안 하는 것 이 좋다고 인식하고 있기 때문이다. 또한 초등학교 고학년이 예뻐 지기 위해서 화장행동을 보이는 예전의 화장행동 분석 결과 $\mathrm{Kim}$
\& Jin (2017)와 다른 연구결과를 도출하였다. 초등학교 고학년은 $\mathrm{TV}$ 나 인터넷, 대중매체를 통해 화장법도 배우고 화장한 모습을 동 영상이나 사진으로 찍어 친구들과 공유함으로써, 외모에 대해 관 심 받고 인정받는 것을 즐긴다(Oh et al., 2012). 이러한 초등학생 의 사회적인 현상으로 요즘 화장의 트렌드에 맞춰 '한 듯 안 한 듯 한' 투명화장을 선호하는 영향력으로 화장은 색조에 관심 있을 거 라는 관점에서 피부에 관심이 있다는 결론은 어떤 면에서 의미 있 는 영향을 미쳤다고 판단된다. 연령이 다른 연구에서는 청소년의 연령이 높을수록 외모 관심도가 더 높게 나타났다(Kim \& Kwon, 2014).

둘째, 초등학교 고학년의 외모 관심 정도는 외모만족도와 화장품 사용행동 및 화장할 때의 심리적 기대감에 영향을 미친다.

연구결과 초등학교 고학년의 외모관심도가 높을수록 외모만족도 와 화장에 대한 심리적 기대감이 높음을 알 수 있다. 이는 초등학교 고학년은 외모관심도가 높아지면서 올바른 화장품 사용과 건전한 화장문화로 타인에게 자신을 자신이 원하는 모습으로 보이도록 하 기(Kim \& Kim, 2019) 위해 노력하며 이러한 것을 통해 자신감과 사회성 등이 증가함에 따라 외모만족도와 화장할 때의 심리적 기대 감이 높아진다고 추측된다.

셋째, 초등학교 고학년의 화장할 때의 심리적 기대감은 외모만족 도와 자아존중감에 영향을 미친다.

연구결과 초등학교 고학년은 화장에 대한 심리적 기대감이 높을 수록 자아존중감이 높음을 알 수 있다. 이는 Park (2017)의 자기 역량지각은 화장행동에 많은 영향을 준 것을 알 수 있다. 신체 이미 지나 외모관리, 화장행동을 통해 자아존중감과 부족한 본인의 역량 에 대해 회복하고자 하며, 이러한 미적 행동이 역량지각이나 자존 감에 긍정적인 영향을 줄 수 있음을 시사한다는 연구결과와 유사하 다. 이러한 보편적인 미의 대한 관심은 초등학생에게도 존재해 왔 으며 이를 표현하는 방법 자체가 조금 더 활성화되기 시작하였다. 화장품의 사용법, 화장하는 기술, 저렴한 화장품의 보급 등으로 초 등학생들 또한 자신을 가꾸고 꾸미는 것에 많은 노력과 시간을 할 애하고 있다. 초등학교 고학년의 사이에서 단순히 화장을 한다는 것이 자신을 가꾸고 꾸미는 것에서 벗어나 또래 집단 사이에서 자 신을 적극적으로 표현하고 드러내는 하나의 방법으로 자리 잡기 시 작한 것이다. Kang (2014)는 초등학교 고학년생에게 화장행동은 또 다른 언어로써 자신을 표출하는데 매우 중요한 영향을 끼친다고 확인하였다.

그러나 본 연구는 초등학교 고학년의 외모 관심, 화장실태와 화 장행동 화장의 심리적 기대감, 외모만족도, 자아존중감 등의 조사 시 그 참여자를 더 여러 곳의 지역과 학년별로 나누어 실시되지 못 했던 것이 자료를 일반화되지 못한다. 따라서 조사 지역을 확대하 고 다양한 학년으로 연구가 이루어져야 할 것이다.

외모에 대한 의식이 사회 변화로 인한 초등학생에게 무분별한 화 
장품 사용에 대한 안전성 인식과 올바른 자아상을 위한 건전한 화 장문화의 연구 등이 진행될 경우, 본 연구가 기초 자료로 사용되었 으면 하는 바람이다.

This work is part of the Jin-hee Ryu's M.Sc. thesis at the Konkuk University, Seoul, Korea.

\section{Author's contribution}

JHR designed, performed experiments, analyzed data, and wrote the manuscript. YSK supervised the project. All figures are created by the author and the co-authors. All authors read and approved the final manuscript.

\section{Author details}

Jin-hee Ryu (Graduate student), Department of Cosmetics Engineering, Konkuk University, 120 Neungdong-ro Gwangjin-gu, Seoul 05029, Korea; Young-Sam Kim (Professor), Department of Image Industry, Graduate School of Engineering, Konkuk University, 120 Neungdong-ro Gwangjin-gu, Seoul 05029, Korea.

\section{References}

Kang MJ. A study on the beauty make-up behavior according to self perceived competence in teenage female adolescents. Journal of Korean Society of Design Culture, 20: 1-12, 2014.

Kim MJ, Kim DJ. A study on the usage and purchasing behavior of cosmetics among elementary school students. Korean Society of Cosmetics and Cosmetology, 4: 209-219, 2014.

Kim JS, Jin HJ. Relationships between cosmetics use and family cohesion and adaptation to school life in the upper grade elementary school girl. The Journal of Korea Elementary Education, 28: 303-314, 2017.

Kim KH, Kim JH. Relationships among cosmetics use patterns, makeup motives and self-esteem in elementary school students. Korean Society of Cosmetics and Cosmetology, 9: 245-261, 2019.

Kim HJ, Kwon HJ. A study on behavior petten of purchase and usage of cosmetic according to interest in appearance of adolescents. Asian Journal of Beauty and Cosmetology, 12: 353-359, 2014.

Kwon TI, Heo HS. Appearance satisfaction and self-esteem of the eyelash cosmetic Conditions. Asian Journal of Beauty and Cosmetology, 17: 295-306, 2019.

Oh B, Kim SN, Lee JM, Jin YM. The influence of interest in beauty and its information by adolescents. Journal of the Korean Society of Cosmetology, 18: 515-522, 2012.

Park JY. Study on makeup consciousness and beauty care behavior of elementary, middle and high school students. Journal of Korean Society of Design Culture, 23: 377-385, 2017.

Park SA, Kim JY. A study of children's satisfaction with their appearance and body, and the current status of their cosmetics use. Jounal of The Korean Society of Cosmetology, 13: 458-466, 2007. 


\section{국문초록}

\section{초등학교 고학년의 외모관심도가 화장행동과 자아존중감에 미치는 영향}

유진희 ${ }^{1}$, 김영삼 ${ }^{2 *}$

${ }^{1}$ 건국대학교 화장품공학과, 서울, 한국

${ }^{2}$ 건국대학교 산업대학원 이미지산업학과, 서울, 한국

목적: 본 연구는 초등학교 고학년의 외모관심도가 화장품 사용실태와 화장행동에 영향을 미치는가를 확인하고, 나아가 그들의 화 장행동이 외모만족도와 자아존중감에는 어떤 영향을 미치는지를 알아보았다. 방법: 11 세-12세 남, 여 초등학교 고학년을 대상 으로 자료를 수집하였고, SPSS WIN 25.0 프로그램을 이용하여 분석하였으며, $t$-test, one-way ANOVA, $\chi^{2}$ (Chi-square)-test, correlation, multiple Regression을 실시하였다. 결과: 초등학교 고학년의 외모관심도가 높을수록 외모만족도가 높음을 알 수 있었 으며, 화장품 사용실태와 화장행동 중 학교 내 화장에 대한 인식, 화장품 구입 주체, 화장품 구입 경로, 화장을 하는 이유, 화장법 등 에서도 외모관심도 수준이 높은 학생이 그렇지 않은 학생보다 자립적이고 화장에 대해 적극적이었으며, 화장에 대한 심리적 기대감 이 높음을 알 수 있었다. 결론: 본 연구를 통해서 초등학교 고학년은 화장에 대한 심리적 기대감이 높을수록 자아존중감이 높음을 알 수 있듯이 초등학교 고학년의 자신의 외모를 부정적으로 평가하는 인식에서 벗어나, 올바른 화장품 사용법과 건전하고 안전한 화장문화를 통해 좋은 이미지를 형성과 자신감과 사회성 확립에 대한 기대효과에 활용할 수 있을 것이다.

핵심어: 초등학생, 외모관심도, 화장문화, 자아존중감, 화장행동

\section{참고문헌}

강명주. 10 대 여자 청소년의 자기역량지각에 따른 화장행동 연구. 한국디자인문화학회지, 20: 1-12, 2014.

권태일, 허혜순. 속눈썹 미용실태에 따른 외모만족도와 자아존중감. 아시안뷰티화장품학술지, 17: 295-306, 2019.

김경희, 김정하. 초등학생의 화장품 사용실태에 따른 화장동기, 자아존중감의 차이연구. 한국화장품미용학회지, $9: 245-$

$261,2019$.

김지선, 진현정. 초등 고학년 여학생의 화장품 사용과 가족 응집력, 학교생활 적응과의 관계. 한국초등교육, $28: 303-$ 314, 2017.

김미지, 김주덕. 초등학생들의 화장품 사용실태 및 구매 행동에 관한 연구. 한국화장품미용학회지, 4: 209-219, 2014.

김희자, 권혜진. 청소년의 외모관심도에 따른 화장품 사용실태와 구매행태 연구. 아시안뷰티화장품학술지, $12: 353-359$,

2014

박정연. 초·중·고등학생의 화장 인식과 뷰티관리 행동 연구. 한국디자인문화학회지, 23: 377-385, 2017.

박선애, 김주연. 학령기아동의 외모만족도 및 색조화장품 사용실태조사. 한국미용학회지, 13: 458-466, 2007.

오별, 김성남, 이중민, 진용미. 청소년의 뷰티관심도와 정보관심이 뷰티관리행동에 미치는 영향. 한국미용학회지, 18 :

515-522, 2012. 


\section{中文摘要}

\section{小学生外貌兴趣对化妆行为及自尊的影响}

梛眞熙 ${ }^{1}$, 金永三 $^{2 *}$

${ }^{1}$ 建国大学化妆品工学科, 首尔, 韩国

2建国大学产业大学院影像产业学科, 首尔, 韩国

目的: 本研究进一步探讨了小学生的化妆行为对外貌满意度和自尊的影响, 旨在探讨小学生的外貌兴趣对化妆行 为和自尊的影响。方法: 对11-12岁的男、女小学生进行问卷调查, 采用SPSS WIN 25.0软件进行统计分析, 进 行频数分析、百分率、 $t$ 检验、单因素方差分析、 $x^{2}$ 检验和回归分析, 得出以下结果。结果: 研究结果表明, 小学 生对外貌的兴趣越高, 对外貌的满意度越高。此外, 考虑到学校对化妆品的认知、化妆品的购买主体、化妆品 的购买渠道、化妆原因、化妆技巧在化妆品实际使用和化妆行为中的作用, 相貌兴趣水平高的学生被认为比其 他组更独立、更积极地化妆, 表现出更高的化妆心理期望。此外, 研究结果还表明, 心理期望越高, 外貌满意 度和自尊越高。结论: 高年级小学生对化妆的心理期望越高, 自尊越高。研究结果有助于国小高年级学生通过适 当使用化妆品和良好的化妆文化，形成良好的形象、自信和社交能力，而不是克服对自身外表的负面认知。

关键词: 小学生, 外貌兴趣, 化妆文化, 自尊, 化妆行为 
